\title{
BMJ Global Health Availability and affordability of medicines and cardiovascular outcomes in 21 high-income, middle-income and low-income countries
}

\author{
Clara Kayei Chow, ${ }^{1}$ Tu Ngoc Nguyen (D , ${ }^{1}$ Simone Marschner, ${ }^{1}$ Rafael Diaz, ${ }^{2}$ \\ Omar Rahman, ${ }^{3}$ Alvaro Avezum, ${ }^{4}$ Scott A Lear, ${ }^{5}$ Koon Teo, ${ }^{6}$ Karen E Yeates, ${ }^{7}$ \\ Fernando Lanas, ${ }^{8}$ Wei Li, ${ }^{9}$ Bo Hu, ${ }^{9}$ Patricio Lopez-Jaramillo, ${ }^{10}$ Rajeev Gupta, ${ }^{11}$ \\ Rajesh Kumar (D) , ${ }^{12}$ Prem K Mony, ${ }^{13}$ Ahmad Bahonar, ${ }^{14}$ Khalid Yusoff, ${ }^{15,16}$ \\ Rasha Khatib, ${ }^{17,18}$ Khawar Kazmi, ${ }^{19}$ Antonio L Dans, ${ }^{20}$ Katarzyna Zatonska, ${ }^{21}$ \\ Khalid F Alhabib, ${ }^{22}$ Iolanthe Marike Kruger, ${ }^{23}$ Annika Rosengren, ${ }^{24}$ Sadi Gulec, ${ }^{25}$ \\ Afzalhussein Yusufali, ${ }^{26}$ Jephat Chifamba, ${ }^{27}$ Sumathy Rangarajan, ${ }^{6}$ \\ Martin McKee (D) , ${ }^{28}$ Salim Yusuf, ${ }^{6}$ On behalf of the PURE Study
}

To cite: Chow CK, Nguyen TN, Marschner S, et al. Availability and affordability of medicines and cardiovascular outcomes in 21 high-income, middleincome and low-income countries. BMJ Global Health 2020;5:e002640. doi:10.1136/ bmjgh-2020-002640

Handling editor Sanne Peters

- Additional material is published online only. To view, please visit the journal online (http://dx.doi.org/10.1136/ bmjgh-2020-002640).

Received 14 April 2020 Revised 6 September 2020 Accepted 10 September 2020

Check for updates

C Author(s) (or their employer(s)) 2020. Re-use permitted under CC BY-NC. No commercial re-use. See rights and permissions. Published by BMJ.

For numbered affiliations see end of article.

Correspondence to

Clara Kayei Chow;

clara.chow@sydney.edu.au

\section{ABSTRACT}

Objectives We aimed to examine the relationship between access to medicine for cardiovascular disease (CVD) and major adverse cardiovascular events (MACEs) among people at high risk of CVD in high-income countries (HICs), upper and lower middle-income countries (UMICs, LMICs) and low-income countries (LICs) participating in the Prospective Urban Rural Epidemiology (PURE) study. Methods We defined high CVD risk as the presence of any of the following: hypertension, coronary artery disease, stroke, smoker, diabetes or age $>55$ years. Availability and affordability of blood pressure lowering drugs, antiplatelets and statins were obtained from pharmacies. Participants were categorised: group 1-all three drug types were available and affordable, group 2-all three drugs were available but not affordable and group 3-all three drugs were not available. We used multivariable Cox proportional hazard models with nested clustering at country and community levels, adjusting for comorbidities, sociodemographic and economic factors.

Results of 163466 participants, there were 93200 with high CVD risk from 21 countries (mean age 54.7, $49 \%$ female). Of these, $44.9 \%$ were from group $1,29.4 \%$ from group 2 and $25.7 \%$ from group 3. Compared with participants from group 1, the risk of MACEs was higher among participants in group 2 (HR 1.19, 95\% Cl 1.07 to 1.31), and among participants from group 3 (HR 1.25, 95\% Cl 1.08 to 1.50).

Conclusion Lower availability and affordability of essentia CVD medicines were associated with higher risk of MACEs and mortality. Improving access to CVD medicines should be a key part of the strategy to lower CVD globally.

\section{BACKGROUND}

Although cardiovascular disease (CVD) mortality has decreased in high-income

\section{Key questions}

What is already known?

- Our previous study, using data from cross-sectiona surveys at baseline in Prospective Urban Rura Epidemiology study, showed that those with cardiovascular disease (CVD) living in communities where medicines are unavailable or unaffordable are less likely to be on treatment or to have their blood pressure controlled.

- However, no study has prospectively documented the impact of availability and affordability of CVD medicines on CVD outcomes.

What are the new findings?

- We found that essential CVD medicines were unavailable and unaffordable for a large proportion of communities where the individuals with a high risk of CVD were living, particularly in lower-middleincome and low-income countries.

- After accounting for sociodemographic and economic factors, education and comorbidities, the unavailability and unaffordability of essential CVD medicines were associated with a higher risk of major adverse cardiovascular events.

- Our analyses are unique because we used standardised methods to assess availability, affordability and event rates in 21 countries and 592 urban and rural communities.

countries (HICs), it has remained high in lower-income countries (LICs) and middleincome countries, ${ }^{1}$ threatening the achievement of the United Nation's Sustainable Development Goal 3, which includes a target to reduce premature mortality from noncommunicable disease by a third by $2030 .^{2}$ 


\section{Key questions}

What do the new findings imply?

- These findings highlight the importance of ensuring the availability and affordability of essential CVD medicines globally, especially in LMICs. This is in line with the WHO's 'Global Action Plan for the Prevention and Control of NCDs 2013-2020' which has a set target of $80 \%$ availability of affordable essential medicines for NCDs, with least $50 \%$ of the eligible people receiving such treatment.

- The study findings imply that affordability in particular is crucial in high, middle-income and low-income settings, and hence likely that without affordable access to essential cardiovascular medicines, it will continue to be a barrier to good medication compliance and cardiovascular outcomes.

Access to affordable and effective medicines has contributed to the decline in HICs, but they are either unavailable or unaffordable for many people living in middleincome countries and LICs. ${ }^{3}{ }^{4}$ The WHO and World Heart Federation have set a goal towards achieving the target that at least $50 \%$ of eligible people receive drug therapy and counselling to prevent heart attacks and stroke. ${ }^{5}$

We have previously shown, using data from crosssectional surveys at baseline in the Prospective Urban and Rural Epidemiology (PURE) study, that those with CVD living in communities where medicines are unavailable or unaffordable are less likely to be on treatment ${ }^{3}$ or to have their blood pressure (BP) controlled. ${ }^{6}$ However, no study has followed up populations in HIC, middleincome countries and LICs over time to quantify any impact of availability and affordability of CVD medicines on CVD outcomes. Follow-up data from PURE are now available, making it possible, for the first time using consistent methods in HICs, middle-income countries and LICs, to answer this question.

\section{METHODS}

\section{Study design and participants}

We analysed data from the PURE study, which has now recruited 192550 participants aged 35-70 years from 23 countries. Follow-up data are now available for 174345 participants from 21 countries (follow-up is still ongoing in the remaining participants). We included participants with complete follow-up data for this analysis. We also used the linked EPOCH (the Environmental Profile of a Community's Health) data ( $\mathrm{n}=163$ 466), which captures objective and subjective measures of environmental and societal factors that can influence CVD in the communities where PURE is undertaken. ${ }^{7}$ The EPOCH instrument comprised of two parts: EPOCH 1 is an objective environmental audit tool in which trained researchers directly observe and systematically record physical aspects of the environment using a pro-forma, with standardised operational definitions, and EPOCH 2 is an interviewer administered questionnaire that captures perceptions about the community from PURE participants living in that community.

Participants were defined as having high risk of CVD if they had any of the following conditions: history of hypertension, coronary artery disease, stroke, diabetes, age $>55$, former or current smoker. ${ }^{8}$

PURE recruited participants from different HICs, middle-income countries and LICs, making it possible to investigate the impact of availability and affordability of CVD medicines on adverse health outcomes across communities at varying economic levels. The countries included in the PURE study represented countries in various stages of economic development (table 1). The countries were grouped based on the World Bank income classification in 2006 when the study was initiated. We recognise that a few countries changed their income category over the course of the study but for simplicity, all countries remain in their original income categories. Details of the PURE study design were described in previous publications. ${ }^{369-11}$

\section{Data collection}

Data on availability and costs of medicines were obtained using the EPOCH instrument. One community pharmacy in each community was visited to collect information about availability and costs of medicines. ${ }^{72}$ Field researchers were instructed to gather information for a list of medications and if more than one medication trade brand existed, to collect information about the most common trade name for each of these medicine classes as identified by the pharmacist.

As previously described, the baseline data collection for PURE was conducted by trained interviewers using standardised questionnaires to obtain information at the household and individual levels. At the household level, this included information on income and expenditure on food per month, and at individual level, this included sociodemographic information, medical history, CVD risk factors and medicine use. ${ }^{10}$ Medication lists were collected for all participant at baseline. Regular medication use was defined as taking medicine at least once per week in the last month. Medications were recorded by trained staff who were instructed to directly inspect the medication or prescriptions. ${ }^{9}$ Medicines were centrally coded into medicine classes.

\section{Definition of essential CVD medicines}

In this study, 10 medications were defined as essential CVD medicines: captopril, enalapril, ramipril, metoprolol, atenolol, amlodipine, hydrochlorothiazide, simvastatin, atorvastatin and aspirin. ${ }^{9}{ }^{13}$ These 10 medications were categorised into three types: (1) BP lowering drugs (captopril, enalapril, ramipril, metoprolol, atenolol, amlodipine and hydrochlorothiazide), (2) antiplatelets (aspirin) and (3) statins (atorvastatin and simvastatin). 
Table 1 Countries included in this study with number of communities, households and participants at high cardiovascular risk

\begin{tabular}{|c|c|c|c|c|}
\hline & $\begin{array}{l}\text { Number of } \\
\text { communities }\end{array}$ & $\begin{array}{l}\text { Number of } \\
\text { households }\end{array}$ & All participants & $\begin{array}{l}\text { Number of participants at } \\
\text { high CVD risk (\% of all) }\end{array}$ \\
\hline Total & 592 & 74281 & 150185 & 93200 \\
\hline High-income countries & 113 & 9815 & 17214 & 12032 \\
\hline Canada & 69 & 6158 & 10314 & 7461 (72.3) \\
\hline Saudi Arabia & 18 & 636 & 1494 & $760(50.9)$ \\
\hline Sweden & 23 & 2372 & 3907 & $3011(77.1)$ \\
\hline United Arab Emirates & 3 & 649 & 1499 & $800(53.4)$ \\
\hline Upper middle-income countries & 117 & 21440 & 39180 & 27189 \\
\hline Argentina & 20 & 4305 & 7509 & $5558(74.0)$ \\
\hline Brazil & 14 & 3636 & 6079 & 4625 (76.1) \\
\hline Chile & 5 & 1934 & 3521 & $2634(74.8)$ \\
\hline Malaysia & 28 & 6525 & 12954 & $7901(61.0)$ \\
\hline Poland & 4 & 1294 & 2031 & $1662(81.8)$ \\
\hline South Africa & 8 & 1658 & 3029 & $1906(62.9)$ \\
\hline Turkey & 38 & 2088 & 4057 & $2903(71.6)$ \\
\hline Lower middle-income countries & 207 & 28142 & 59737 & 35458 \\
\hline Colombia & 55 & 3685 & 6896 & $4360(63.2)$ \\
\hline China & 93 & 19738 & 42861 & $25533(59.6)$ \\
\hline Iran & 20 & 2400 & 6013 & $2904(48.3)$ \\
\hline Palestine & 35 & 1055 & 1574 & $1058(67.2)$ \\
\hline Philippines & 4 & 1264 & 2393 & $1603(67.0)$ \\
\hline Low-income countries & 68 & 3543 & 7791 & 18521 \\
\hline Bangladesh & 55 & 1174 & 2926 & $1410(48.2)$ \\
\hline Pakistan & 4 & 838 & 1713 & $1161(67.8)$ \\
\hline Tanzania & 6 & 818 & 1910 & 847 (44.3) \\
\hline Zimbabwe & 3 & 713 & 1242 & $808(65.1)$ \\
\hline India & 87 & 11341 & 26263 & $14295(54.4 \%)$ \\
\hline
\end{tabular}

High risk of CVD was defined as having any of the following conditions: history of hypertension, coronary artery disease, stroke, diabetes, age $>55$, former or current smoker.

$\mathrm{CD}$, cardiovascular disease.

\section{Definitions of availability and affordability of the essential CVD medicines}

We used standardised definitions to measure availability and affordability. They are limited measures, and do not account for other factors related to access to these medications such as cost/distance to travel to pharmacies, the provision of free medications to some or all people in some communities. Medications were available if they were on the shelf of the pharmacy at the time of the visit, and cost was the price medications were sold for. We defined our main two exposures as follows.

Availability of essential CVD medicines was defined as the presence of all three types of essential CVD medications (BP lowering drugs, antiplatelets and statins) at any dose in the selected pharmacy on the day of the survey.

Affordability of essential CVD medicines was assessed using the total monthly costs of all three types of essential CVD medication types at standard doses and recommended frequencies. ${ }^{9}$ The lowest-cost drug in each of these three types of essential CVD medicine was chosen for the estimation of the total monthly cost. Combined costs of the three types were defined as affordable if they constituted less than $20 \%$ of a household's capacity to pay as per previous publications from PURE. ${ }^{3614}$ Household capacity-to-pay is the household income remaining after basic subsistence needs, defined as the household monthly income spent on food, have been met. ${ }^{15}$

\section{Definition of outcomes}

Primary outcomes were major adverse cardiovascular events (MACEs) — a composite of CVD mortality, stroke, myocardial infarction and heart failure), and all-cause mortality. Participants and their family were contacted at regular intervals to obtain information on specific events. Follow-up of participants was performed at least every 3 years. All follow-up visits were conducted by 
visiting households, by telephone calls or by inviting the participants to the central research offices to complete the follow-up visit. Events were characterised centrally in each country by trained physicians, using standardised definitions, verbal autopsies and review of documents. ${ }^{11}$

\section{Statistical analysis}

All statistical analyses were performed with SAS V.9.4 and R. Continuous variables were presented as mean (SD or median, range), and categorical variables as frequency and percentage. Data were, in some instances, presented as groups by overall country economic status for ease of presentation, however it is acknowledged that socioeconomic heterogeneity exists within many countries also. Models hence account for household and individuallevel socioeconomic measures.

We examined the combination of availability and affordability through a combined variable. Participants were classified into three groups according to the availability and affordability of the three types of medications (BP lowering, statin and antiplatelets): group 1-individuals from communities where all three were available and affordable, group 2-individuals from communities where all three were available but not affordable to them and group 3-individuals from communities where all three were not available. Group 1 was used as the reference group. We also performed additional analysis on the association between the number of essential CVD medicines available and MACEs.

Multilevel Cox proportional hazard models that account for nested clustering at country and community levels were applied to calculate the HRs and their 95\% CIs for MACEs and all-cause mortality. The clustering was incorporated using a frailty model, which involves introducing a shared random effect into the proportional hazard model for participants from the same cluster. ${ }^{16}$ Nesting of community within country was incorporated by nesting the community random effect within the country random effect. We adjusted for covariates as in previous publications from the PURE study, including age, gender, educational level, smoking status, history of hypertension, coronary heart disease, stroke, diabetes, number of people in household, rural/urban living and the Global Wealth Index country specific tertiles. ${ }^{6}$ The Wealth index was created using information collected on the household possessions from the PURE baseline questionnaire. Items included electricity, car, computer, television, motorbike, livestock, fridge, other four-wheeler vehicle, washing machine, stereo, bike, kitchen mixture, phone, land and kitchen window. Binary classification of yes/no was created for each item and then a principal component analysis was used to extract the component with largest eigenvalue. Each household was then assigned to a score based on factor loadings.

Data from India were presented separately from other LICs to be consistent with previous publications from the PURE study. India was seen to be very different from all of the other LICs with respect to availability of cardiovascular medicines due to the large domestic pharmaceutical industry and the practice that many medicines are available over the counter and without prescription, as well as to particular policies, such as selective process controls. ${ }^{3}{ }^{314}$

\section{Patient and public involvement}

Patients or the public were not involved in the design, or conduct, or reporting or dissemination plans of our research.

\section{RESULTS}

There were 163466 adults with follow-up data in the PURE database at the time of analysis (August 2019) and among these 93200 adults were defined as having high risk of CVD, from 592 communities and 21 countries (table 1). Among those identified as high risk, 39 $968(42.9 \%)$ had two or more risk factors, and 53232 $(57.1 \%)$ had only one single factor among the defined risk factors.

The mean age was 54.7 years, $49.0 \%$ were female. Baseline characteristics of these participants are presented in table 2. Participants from communities with no medications available had the highest prevalence of poor education, low wealth index, rural living and had lower use of preventative medications at baseline (table 2).

The percentages of individuals with high CVD risk from communities where all three types of CVD medicines were available were $74.3 \%$ overall, $97.0 \%$ in HICs, $85.2 \%$ in UMICs, $57.8 \%$ in LMICs, $24.1 \%$ in LICs and $88.3 \%$ in India. The percentages of high CVD risk individuals from communities where all three types of CVD medicines were available and affordable (group 1) was $44.9 \%$ overall, $94.8 \%$ in HICs, $57.2 \%$ in UMICs, $28.6 \%$ in LMICs, $10.1 \%$ in LICs and $29.9 \%$ in India (figure 1).

Overall, BP lowering medication had the highest rate of availability (95.1\% of the communities), followed by antiplatelets $(92.9 \%)$, and $78.5 \%$ for statins. The availability of these three types of essential CVD medicines was consistently lower in LICs compared with countries with higher income, particularly for statins (except for India, where medicines were relatively widely available) (online supplemental table S1 and S2).

After 9 years of follow-up in this high-risk population, the incidence of MACEs was $6.74 \%(2482 / 36330)$ in participants in group 1 (age standardised rate $6.83 \%$ ), $8.67 \%(1825 / 21065)$ in participants in group 2 (age standardised rate $8.63 \%)$ and $7.99 \%(1583 / 19810)$ in participants in group 3 (age standardised rate $8.06 \%$ ). Using group 1 as the reference group, the risk of MACEs was greater in group 2 (all three types of CVD medicines were available but not affordable), with the adjusted $\mathrm{HR}=1.19,95 \%$ CI 1.07 to $1.31, \mathrm{p}<0.001$ and in group 3 (all three types of CVD medicines were not available), with the adjusted $\mathrm{HR}=1.27,95 \%$ CI 1.08 to $1.50, \mathrm{p}=0.004$. (figure 2) 
Table 2 Baseline characteristics of participants with high risk of CVD

\begin{tabular}{|c|c|c|c|c|c|}
\hline & $\begin{array}{l}\text { Total high risk } \\
\text { participants } \\
n=93200\end{array}$ & $\begin{array}{l}\text { Group } 1 \text {-available } \\
\text { and affordable } \\
\mathrm{n}=34974\end{array}$ & $\begin{array}{l}\text { Group 2- } \\
\text { available but } \\
\text { unaffordable } \\
n=22918\end{array}$ & $\begin{array}{l}\text { Group 3- } \\
\text { unavailable } \\
n=20022\end{array}$ & $\begin{array}{l}\text { Missing } \\
\mathrm{n}=15286\end{array}$ \\
\hline Age (years), median (SD), missing: 2 & $54.7(9.6)$ & $54.4(9.3)$ & $54.9(9.7)$ & $54.5(9.7)$ & $55.2(9.7)$ \\
\hline Female, $\mathrm{n}(\%)$, missing: 1 & 45700 (49.0\%) & $16621(47.5 \%)$ & $11419(49.8 \%)$ & $9423(47.1 \%)$ & $8237(53.9 \%)$ \\
\hline \multicolumn{6}{|l|}{ Educational level, n (\%), missing: 261} \\
\hline None & 13924 (15.0\%) & $2542(7.3 \%)$ & $4136(18.1 \%)$ & $4679(23.5 \%)$ & $2567(16.8 \%)$ \\
\hline Primary school & $27909(30.0 \%)$ & $7318(20.9 \%)$ & $7639(33.5 \%)$ & $7214(36.2 \%)$ & $5738(37.6 \%)$ \\
\hline Secondary/high school & 32637 (35.1\%) & $12661(36.2 \%)$ & 9029 (39.6\%) & $6536(32.8 \%)$ & $4411(28.9 \%)$ \\
\hline Trade school & $4432(4.8 \%)$ & $2536(7.3 \%)$ & $690(3.0 \%)$ & $589(3.0 \%)$ & $617(4.0 \%)$ \\
\hline College/university & $13740(14.8 \%)$ & $9733(27.9 \%)$ & $1269(5.6 \%)$ & $850(4.3 \%)$ & $1888(12.4 \%)$ \\
\hline Unknown & $297(0.3 \%)$ & $147(0.4 \%)$ & $44(0.2 \%)$ & $84(0.4 \%)$ & $22(0.1 \%)$ \\
\hline \multicolumn{6}{|c|}{ Global Wealth Index country specific tertiles, missing: 188} \\
\hline Tertile 1 & $30357(32.6 \%)$ & $7499(21.4 \%)$ & $8099(35.4 \%)$ & $9493(47.5 \%)$ & $5266(34.8 \%)$ \\
\hline Tertile 2 & $30676(33.0 \%)$ & $11091(31.7 \%)$ & $7963(34.8 \%)$ & $6477(32.4 \%)$ & $5145(34.0 \%)$ \\
\hline Tertile 3 & $31979(34.4 \%)$ & $16378(46.8 \%)$ & $6847(29.9 \%)$ & $4013(20.1 \%)$ & $4741(31.3 \%)$ \\
\hline \multicolumn{6}{|l|}{ Smoking status, $\mathrm{n}(\%)$, missing: 723} \\
\hline Former smoker & $17156(18.6 \%)$ & $9100(26.1 \%)$ & $2669(11.8 \%)$ & $2232(11.3 \%)$ & $3155(20.8 \%)$ \\
\hline Current smoker & $30926(33.4 \%)$ & $9695(27.8 \%)$ & $8503(37.5 \%)$ & $7743(39.2 \%)$ & $4985(32.8 \%)$ \\
\hline Never smoke & $44395(48.0 \%)$ & $16044(46.1 \%)$ & $11525(50.8 \%)$ & $9767(49.5 \%)$ & $7059(46.4 \%)$ \\
\hline $\begin{array}{l}\text { Number of people in the household, } \\
\text { median (Q1, Q3) missing: } 11386\end{array}$ & $3.0(2.0-4.0)$ & $3.0(2.0-5.0)$ & $4.0(2.0-5.0)$ & $3.0(2.0-5.0)$ & $3.0(2.0-5.0)$ \\
\hline \multicolumn{6}{|l|}{ Urban/rural living, $n$ (\%), missing: 0} \\
\hline Urban & $53151(57.0 \%)$ & $26163(74.8 \%)$ & $13208(57.6 \%)$ & $5623(28.1 \%)$ & $8157(53.4 \%)$ \\
\hline Rural & $40049(43.0 \%)$ & $8811(25.2 \%)$ & $9710(42.4 \%)$ & $14399(71.9 \%)$ & $7129(46.6 \%)$ \\
\hline $\begin{array}{l}\text { History of hypertension, } n(\%) \text {, missing: } \\
205\end{array}$ & $31546(33.9 \%)$ & $12638(36.2 \%)$ & $7592(33.2 \%)$ & $5869(29.4 \%)$ & $5447(35.7 \%)$ \\
\hline History of diabetes, $\mathrm{n}(\%)$, missing: 159 & $12522(13.5 \%)$ & $5524(15.8 \%)$ & $3182(13.9 \%)$ & $1847(9.3 \%)$ & $1969(12.9 \%)$ \\
\hline $\begin{array}{l}\text { History of coronary heart disease, } \mathrm{n}(\%) \text {, } \\
\text { missing: } 172\end{array}$ & $5774(6.2 \%)$ & $2267(6.5 \%)$ & $1219(5.3 \%)$ & $1401(7.0 \%)$ & $887(5.8 \%)$ \\
\hline History of stroke, n (\%), missing: 179 & $2547(2.7 \%)$ & $847(2.4 \%)$ & $632(2.8 \%)$ & $644(3.2 \%)$ & $424(2.8 \%)$ \\
\hline \multicolumn{6}{|l|}{ Use of preventative medication: } \\
\hline Antiplatelets & $6037(6.5 \%)$ & $3114(8.9 \%)$ & $861(3.8 \%)$ & $836(4.2 \%)$ & $1226(8.0 \%)$ \\
\hline Statins & $4761(5.1 \%)$ & $3189(9.1 \%)$ & 508 (2.2\%) & 239 (1.2\%) & 825 (5.4\%) \\
\hline BP lowering & 20852 (22.4\%) & $9517(27.2 \%)$ & $4174(18.2 \%)$ & 2967 (14.8\%) & $4194(27.4 \%)$ \\
\hline
\end{tabular}

Group 1-individuals from communities where all three were available and affordable, group 2-individuals from communities where all three were available but not affordable to them, group 3-individuals from communities where all three were not available.

High risk of CVD was defined as having any of the following conditions: history of hypertension, coronary artery disease, stroke, diabetes, age $>55$, former or current smoker.

All p-values for differences between groups were $<0.001$

$\mathrm{BP}$, blood pressure; CVD, cardiovascular disease.

The all-cause mortality rate was $8.88 \%(8210 / 92435)$ in all high-risk participants. It was higher, at $12.64 \%$ in group 2 (age standardised rate $12.52 \%$ ), and at $9.45 \%$ in group 3 (age standardised rate $9.50 \%$ ), compared with $5.84 \%$ in group 1 (age standardised rate $5.99 \%$ ). In Cox proportional hazard models with participants from group 1 (all three types of CVD medicines were available and affordable) as the reference group, the risk of allcause mortality was also greater with both lack of availability and/or affordability. Compared with group 1, the risk of all-cause mortality was greater in group 2 , with the adjusted $\mathrm{HR}=1.20,95 \%$ CI 1.08 to $1.32, \mathrm{p}<0.001$ and in group 3, with the adjusted HR=1.25, 95\% CI 1.04 to 1.50 , $\mathrm{p}=0.015$ (figure 3 ).

The percentages $(95 \%$ CI) of MACEs and mortality by availability and affordability during follow-up are presented in online supplemental appendix table S3. Unadjusted HRs for MACEs and all-cause mortality by availability and affordability are shown in online supplemental appendix table S4.

Similar results were found through sensitivity analyses using different age thresholds ( $>60$ or $>65$, online 


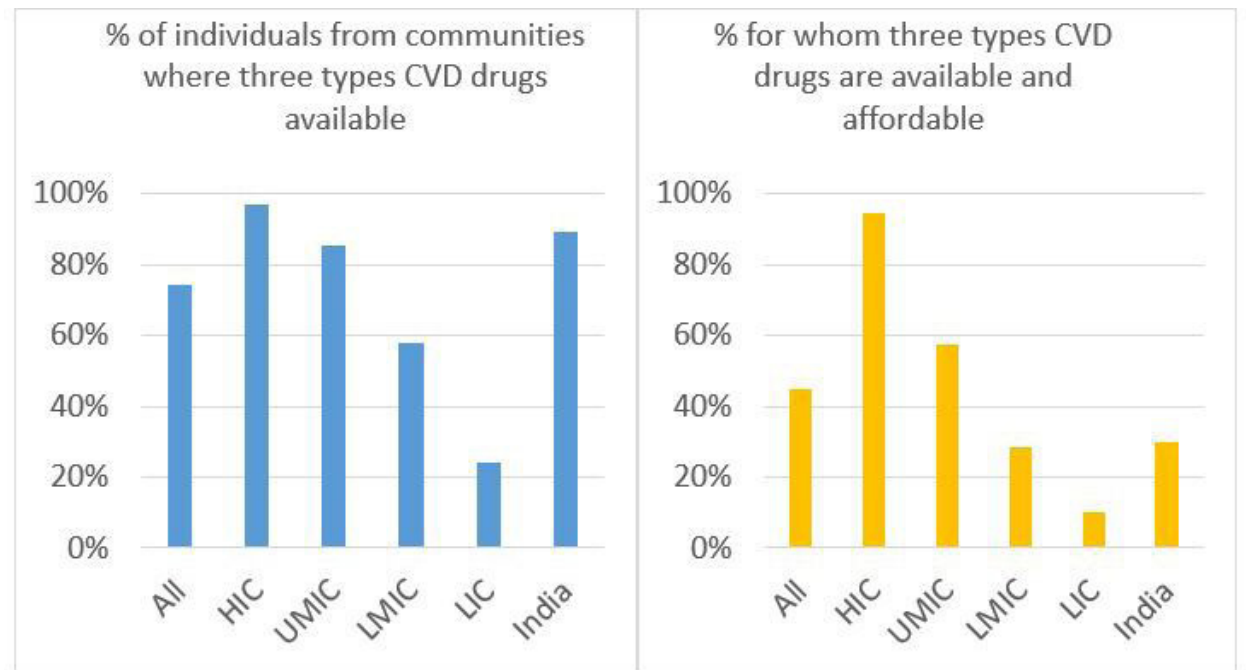

Figure 1 Percentages of individuals with high CVD risk from communities where three types of CVD medicines are available (left) and affordable (right). CVD, cardiovascular disease; HIC, high-income countries; LICs, low-income countries; LMICs, lower middle-income countries; UMICs, upper middle-income countries.

supplemental appendix table S5 and S6), different thresholds for capacity to pay $(10 \%$ or $25 \%$, online supplemental appendix tables S7-S9) and different definition of high risk individual (the non-laboratory INTERHEART risk score, ${ }^{17}$ online supplemental appendix tables S10-S13).

The number of medicines available among the 10 studied medications varied considerably (online supplemental appendix figure S1). For each additional drug available, the hazard of MACEs reduced by $5 \%(95 \%$ CI 0.93 to $0.98, \mathrm{p}<0.001$ ) (online supplemental appendix figure S2).

Affordability was a key factor across countries from all income categories. For people living in HICs, the

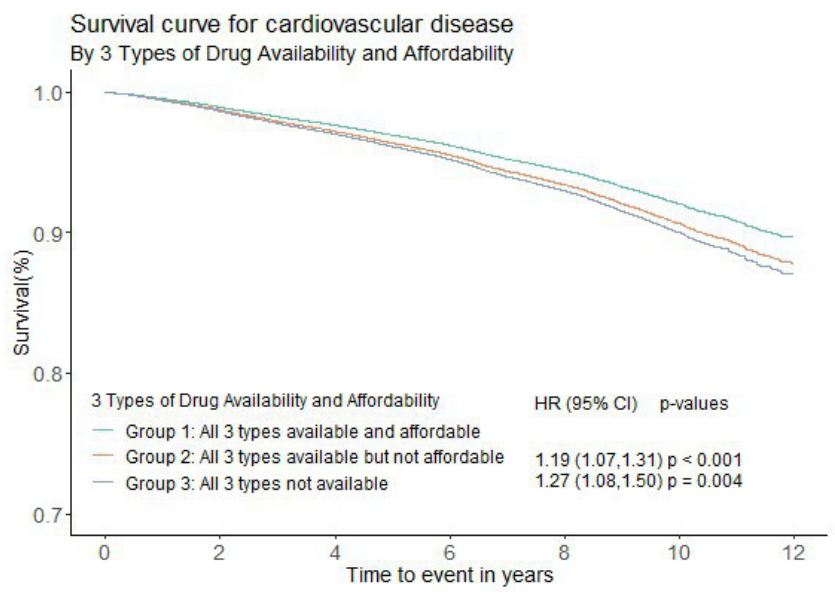

\begin{tabular}{lllllllr} 
Group 1 & 34657 & 33451 & 29683 & 26921 & 23974 & 7385 & 1383 \\
Group 2 & 22737 & 21839 & 18975 & 17257 & 15402 & 6707 & 3220 \\
Group 3 19809 & 18781 & 16183 & 14281 & 11691 & 3772 & 756 \\
\multicolumn{7}{c}{ Numbers at risk }
\end{tabular}

Figure 2 Availability and affordability of three types of CVD medicines and MACEs (group 1 was the reference group). CVD, cardiovascular disease; MACE, major adverse cardiovascular events. impact of affordability on MACEs appeared even higher compared with those living in middle-income countries and LICs. Online supplemental appendix figure S3 presents the adjusted HRs of affordability (not affordable vs affordable) on time to MACEs for each economic group.

\section{DISCUSSION}

In this study, we found that essential CVD medicines were unavailable and unaffordable for a large proportion of communities where the individuals with high risk of CVD were living, particularly in LMICs and LICs. The unavailability and unaffordability of essential CVD medicines was associated with increased risk of MACEs after accounting

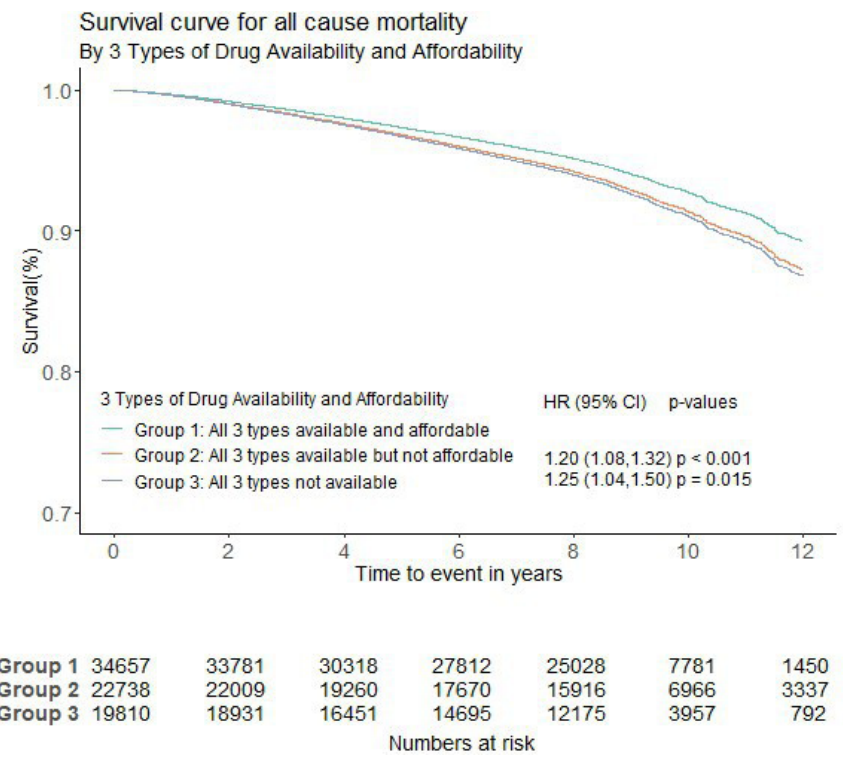

Figure 3 Availability and affordability of three types of CVD medicines and mortality (group 1 was the reference group). CVD, cardiovascular disease. 
for sociodemographic and economic factors, education, comorbidities and accounting for clustering.

Low availability and affordability to cardiovascular medicines in LICs and middle-income countries have been reported in several studies. In a study published in 2010, van Mourik et al found that the overall availability of cardiovascular medicines in 36 countries at all levels of development was poor (26.3\% in public sector, $57.3 \%$ private sector) and cardiovascular medicines were least affordable in the poorest countries. ${ }^{18}$ In a survey of availability and affordability of selected essential medicines for chronic diseases in LICs and middle-income countries conducted by Mendis et al in 2007, the availability of some essential CVD medicines was extremely low in some countries (eg, hydrochlorothiazide: $0.7 \%$ in Pakistan, 5.8\% in Bangladesh; captopril: 0.5\% in Nepal, 5.6\% in Malawi; enalapril: $0.8 \%$ in Malawi; and statin: ranged from $0.1 \%$ to $21 \%$ in the all the surveyed countries), and the affordability of these medicines was also poor. ${ }^{4}$ In another study of hypertension management in 44 LICs and middle-income countries, only $29.9 \%$ of people with hypertension received antihypertensive treatment, and in only $10.3 \%$ was it controlled. ${ }^{19}$ In a recent study conducted by Husain et al based on the WHO online repository of national essential medicines lists for 53 countries, the average availability of the essential CVD medications was $54 \%$ in LICs and lower-middle-income countries (LMICs) and 60\% in HICs and upper-middleincome countries (UMICs). ${ }^{20}$ They also found that affordability was lower in LICs and LMICs than HICs and UMICs for both brand and generic medications. ${ }^{20}$ In our previous publications from the PURE study, overall hypertension control was worst in LICs and LMICs (10.8\%), with poor access to medicines among the reasons for the low frequency of treatment and control of hypertension in these countries. ${ }^{621}$ The data in the majority of these studies are now dated, we need repeat assessments to track medication availability and affordability as these could change over time.

Interestingly, in contrast to our anticipation, the crude rates of MACEs and all-cause mortality were actually higher in group 2 compared with group 3. Group 2 comprised of participants with high risk of CVD that lived in communities where essential CVD medicines were available but unaffordable to them. This may be due to the higher prevalence of comorbidities such as hypertension and diabetes in this group. In addition, the proportion of urban living was also higher in group 2 compared with group 3 ( $57.6 \%$ vs $28.1 \%$, respectively). Urban living may be associated with other factors that can increase the risk of MACEs and all-cause mortality such as anxiety, depression, sedentary lifestyle, high consumption of fast food and diseases related to air pollution, especially in LICs and middle-income countries. This finding may also highlight the fact that affordability was a key factor. Even when the medications are available in the communities, people still could not access them if they could not afford them. In this study, the impact of affordability on MACEs in people living in HICs was even higher compared with those living in LICs and middle-income countries, as shown in the online supplemental appendix figure S3.

\section{Strengths}

Our analyses are unique because we used standardised methods to assess availability, affordability and event rates of MACEs and all-cause mortality from 21 countries and 592 urban and rural communities worldwide.

Our results support previous findings that in LICs and middle-income countries, the availability and affordability of key medicines for the prevention of CVD are low and provide evidence that this affected adversely on outcomes in populations at risk of CVD.

\section{Limitations}

As noted in previous publications from the PURE study, our results capture only part of the costs of treatment, ${ }^{3}$ as we are unable to take into account other costs (such as professional fees or travel or time taken of work to visit a doctor) and hence, we could have overestimated its affordability. In addition, we were also unable to account for policies and other activities of non-governmental organisations in various regions of the world that may provide free medications to some participants in some countries, which may influence medication use and access to variable degrees. We do not have information about how household incomes might have changed during follow-up, which may be important given the economic impact of illness. Also, availability and affordability were only assessed at baseline (but this is inevitable in such a large study in which we aimed to relate these to long-term outcomes) and may have changed over time. Moreover, during the study time, several countries transitioned to other income categories, for example, India: LIC-LMIC (2009), China: LMICUMIC (2013), Colombia: LMIC-UMIC (2008), Iran: LMIC-UMIC (2010). Along with these transitions, their health systems may have changed as well. The availability and affordability of medicines were assessed at the community pharmacy level, therefore it may not necessarily reflect the availability and affordability at different points of care such as pharmacies at public health facilities or private health facilities. The criteria that EPOCH used to collect medicine price entailed surveying the most common trade name for each of these medicine classes identified by the pharmacists. While our method attempted to identify the most available medicine in the pharmacy and its cost, there is variation in availability and price particularly between generic and brand drugs across pharmacies. Availability of a particular CVD medicine may also depend whether the country Essential Medicine Lists include the medicines in the first place. In addition, there may be other aspects of access to healthcare that may have changed, such as number of health workers, availability of diagnostic and therapeutic interventions and we do not have data on these. The criteria used to define high risk patients resulted in having a mixed group of patients that are not at the same level of risk. For the various reasons described above, the 
HRs calculated in these analyses could be underestimated compared to an analysis in which availability and affordability was more more accurately measured.

\section{Implications for practice/policy}

The medicines studied in this paper have been shown to be effective in primary and secondary prevention of CVD events and to reduce mortality, and are recommended in most clinical guidelines but were unavailable in a large proportion of communities in LICs and middle-income countries and even when available they were not always affordable. In a previous publication from the PURE study, both low availability and affordability were associated with low use of CVD medicines. ${ }^{3}$ This points to a plausible explanation of the association with MACEs and mortality.

According to the WHO, essential medicines are those that satisfy the priority healthcare needs of the population. ${ }^{22}$ Essential medicines should be available within functioning health systems at all times, in adequate amounts, in the appropriate dosage, with assured quality and at an affordable price to individuals and communities. ${ }^{22}$ The WHO's Global Action Plan set a target of $80 \%$ availability of affordable essential medicines for noncommunicable diseases worldwide, and at least $50 \%$ of those in need of these medicines by $2025 .{ }^{23}$ This requires addressing the most common reasons for medicines shortages, catalogued in a review conducted by Acosta et $a .^{24}$ These include market-related factors (such as increased demand, voluntary withdrawal, unexpected changes in clinical practice, loss of market interest and relocation of production facilities), supply chain management (structure of the network or supply chain in the country, supply of raw materials and excipients), manufacturing processes (quality concerns, changes in the product formulation, industrial development capacities, production problems), reduced public health funding, political and ethical issues (such as regulatory problems, public policy and social conflicts). In LICs and middleincome countries, the rising prices of medicines, often paid out-of-pocket, mean that they account for up to $70 \%$ of total healthcare expenditure ${ }^{24}$ and can lead to illnessinduced poverty and reduce access to the needed treatment. More research effort and strategies are needed to improve affordability to essential medicines. In a recent publication from the Heart Outcomes Prevention and Evaluation 4 (HOPE-4) study in individuals with new or poorly controlled hypertension from 30 communities in Colombia and Malaysia, free distribution of a fixed dose combination of two antihypertensive drugs and statins substantially improved the Framingham risk score and improved the control of hypertension and low-density lipoprotein (LDL) cholesterol in the participants. ${ }^{25}$ Ensuring access to essential medicine plays a major role in the prevention and control of CVD, which is both important to prevent long-term adverse outcomes and also essential during the current COVID-19 pandemic situation. According to a recent review, the presence of pre-existing CVD was consistently associated with significantly worse outcome in patients with COVID-19. ${ }^{26}$

\section{CONCLUSIONS}

Less availability and affordability of essential CVD medicines were associated with increased risk of MACE and all-cause mortality in this global population from countries of varying income levels. These findings highlight the importance of ensuring that essential CVD medicines are available and affordable for those at high risk of CVD everywhere. Factors associated with availability and affordability of essential CVD medicines must be identified for appropriate care globally.

\section{Author affiliations}

${ }^{1}$ Westmead Applied Research Centre, Faculty of Medicine and Health, The University of Sydney, Sydney, New South Wales, Australia

${ }^{2}$ Estudios Clinicos Latino America, Rosario, Argentina

${ }^{3}$ Independent University, Dhaka, Dhaka District, Bangladesh

${ }^{4}$ International Research Centre, Hospital Alemao Oswaldo Cruz, Sao Paulo, Brazil

${ }^{5}$ Faculty of Health Sciences, Simon Fraser University, Burnaby, British Columbia, Canada

${ }^{6}$ Population Health Research Institute, McMaster University, Hamilton, Ontario,

Canada

${ }^{7}$ Department of Medicine, Queen's University, Kingston, Ontario, Canada

${ }^{8}$ Universidad de La Frontera, Temuco, Chile

${ }^{9}$ Medical Research \& Biometrics Center, National Center for Cardiovascular Diseases, Chinese Academy of Medical Sciences and Fuwai Hospital, Xicheng District, Beijing, China

${ }^{10}$ Masira Research Institute, Universidad de Santander, Bucaramanga, Colombia

${ }^{11}$ Eternal Heart Care Centre and Research Institute, Jaipur, India

${ }^{12}$ Department of Community Medicine and School of Public Health, Post Graduate Institute of Medical Education and Research, Chandigarh, India

${ }^{13}$ St John's Medical College, Bangalore, Karnataka, India

${ }^{14}$ Isfahan Cardiovascular Research Center, Cardiovascular Research Institute, Isfahan University of Medical Sciences, Isfahan, Iran (the Islamic Republic of)

${ }^{15}$ Faculty of Medicine and Health Sciences, UCSI University, Kuala Lumpur, Wilayah Persekutuan, Malaysia

${ }^{16}$ Centre for Translational Research \& Epidemiology, Faculty of Medicine, University Teknologi MARA, Shah Alam, Selangor, Malaysia

${ }^{17}$ Institute for Community and Public Health, Birzeit University, Birzeit, Illinois, Palestine

${ }^{18}$ Advocate Research Institute, Advocate Health Care, Hinsdale, Illinois, USA ${ }^{19}$ Department of Medicine, Aga Khan University, Karachi, Pakistan

${ }^{20}$ Section of Adult Medicine \& Medical Research Unit, University of the Philippines, Manila, Philippines

${ }^{21}$ Department of Social Medicine, Wroclaw Medical University, Wroclaw, Poland

22Department of Cardiac Sciences, King Fahad Cardiac Center, College of Medicine, King Saud University, Riyadh, Saudi Arabia

${ }^{23}$ Africa Unit for Transdisciplinary Health Research, North-West University, Potchefstroom, South Africa

${ }^{24}$ Department of Molecular and Clinical Medicine, University of Gothenburg and Region Västra Götaland, Sahlgrenska University Hospital, Gothenburg, Sweden

${ }^{25}$ Cardiology Department, Ankara University School of Medicine, Ankara, Turkey

${ }^{26}$ Dubai Medical University, Dubai, United Arab Emirates

${ }^{27}$ Physiology Department, University of Zimbabwe College of Health Sciences, Harare, Zimbabwe

${ }^{28}$ Centre for Global Chronic Conditions, London School of Hygiene \& Tropical Medicine, London, UK

Acknowledgements We thank Chinthanie Ramasundarahettige (Statistician, Population Health Research Institute, McMaster University, Hamilton Health Sciences, Hamilton, ON, Canada) for her reviewing of the study proposal and providing the data sets for the analysis, and Amy Von Huben (Statistician, Westmead Applied Research Centre, Faculty of Medicine and Health, University of Sydney, Sydney, New South Wales, Australia) for her support with the statistical 
programming. We wish to acknowledge the additional persons provided in the supplementary appendix who have contributed to the PURE study.

Contributors SY designed the PURE study, obtained the funding and oversaw its conduct since its inception 18 years ago. CKC conceived the analysis plan for the current study. CKC and SM wrote the analysis plan. CKC, SM and TNN conducted all study analyses and interpretation of the results. CKC and TNN wrote the various drafts. SR coordinated the worldwide study. All other authors coordinated the study in their countries and all reviewed and commented on drafts of the paper.

Funding SY is supported by the Mary W Burke endowed chair of the Heart and Stroke Foundation of Ontario. The PURE study is an investigator-initiated study that is funded by the Population Health Research Institute, Hamilton Health Sciences Research Institute (HHSRI), the Canadian Institutes of Health Research, Heart and Stroke Foundation of Ontario, Support from Canadian Institutes of Health Research's Strategy for Patient Oriented Research, through the Ontario SPOR Support Unit, as well as the Ontario Ministry of Health and Long-Term Care and through unrestricted grants from several pharmaceutical companies (with major contributions from AstraZeneca (Canada), Sanofi-Aventis (France and Canada), Boehringer Ingelheim (Germany and Canada), Servier, and GlaxoSmithKline), and additional contributions from Novartis and King Pharma and from various national or local organisations in participating countries. These include Argentina: Fundacion ECLA (Estudios Clínicos Latino America); Bangladesh: Independent University, Bangladesh and Mitra and Associates; Brazil: Unilever Health Institute, Brazil; Canada: this study was supported by an unrestricted grant from Dairy Farmers of Canada and the National Dairy Council (USA), Public Health Agency of Canada and Champlain Cardiovascular Disease Prevention Network; Chile: Universidad de La Frontera [DI13-PE11]; China: National Center for Cardiovascular Diseases and ThinkTank Research Center for Health Development; Colombia: Colciencias (grant 6566-04-18062 and grant 6517-777-58228); India: Indian Council of Medical Research; Malaysia: Ministry of Science, Technology and Innovation of Malaysia (grant number: 100-IRDC/BIOTEK 16/6/21 [13/2007], and 07-05-IFN-BPH 010), Ministry of Higher Education of Malaysia (grant number: 600-RMI/LRGS/5/3 [2/2011]), Universiti Teknologi MARA, Universiti Kebangsaan Malaysia (UKMHejim-Komuniti-15-2010); occupied Palestinian territory: the United Nations Relief and Works Agency for Palestine Refugees in the Near East, occupied Palestinian territory; International Development Research Centre, Canada; Philippines: Philippine Council for Health Research and Development; Poland: Polish Ministry of Science and Higher Education (grant number: 290/W-PURE/2008/0), Wroclaw Medical University; Saudi Arabia: Saudi Heart Association, Saudi Gastroenterology Association, Dr.Mohammad Alfagih Hospital, The Deanship of Scientific Research at King Saud University, Riyadh, Saudi Arabia (Research group number: RG -1436-013); South Africa: The North-West University, SA and Netherlands Programme for Alternative Development, National Research Foundation, Medical Research Council of South Africa, The South Africa Sugar Association, Faculty of Community and Health Sciences; Sweden: Grants from the Swedish state under the Agreement concerning research and education of doctors; the Swedish Heart and Lung Foundation; the Swedish Research Council; the Swedish Council for Health, Working Life and Welfare, King Gustaf V:s and Queen Victoria Freemason's Foundation, AFA Insurance; Turkey: Metabolic Syndrome Society, AstraZeneca, Sanofi Aventis; United Arab Emirates: Sheikh Hamdan Bin Rashid Al Maktoum Award For Medical Sciences and Dubai Health Authority, Dubai.

\section{Competing interests None declared.}

\section{Patient consent for publication Not required.}

Ethics approval Ethics approvals were obtained at each study centre, and all participants provided written informed consent.

Provenance and peer review Not commissioned; externally peer reviewed.

Data availability statement Data are available upon request. The study data are available from the corresponding author upon request.

Supplemental material This content has been supplied by the author(s). It has not been vetted by BMJ Publishing Group Limited (BMJ) and may not have been peer-reviewed. Any opinions or recommendations discussed are solely those of the author(s) and are not endorsed by BMJ. BMJ disclaims all liability and responsibility arising from any reliance placed on the content. Where the content includes any translated material, BMJ does not warrant the accuracy and reliability of the translations (including but not limited to local regulations, clinical guidelines, terminology, drug names and drug dosages), and is not responsible for any error and/or omissions arising from translation and adaptation or otherwise.

Open access This is an open access article distributed in accordance with the Creative Commons Attribution Non Commercial (CC BY-NC 4.0) license, which permits others to distribute, remix, adapt, build upon this work non-commercially, and license their derivative works on different terms, provided the original work is properly cited, appropriate credit is given, any changes made indicated, and the use is non-commercial. See: http://creativecommons.org/licenses/by-nc/4.0/.

\section{ORCID iDs}

Tu Ngoc Nguyen http://orcid.org/0000-0002-8836-8920

Rajesh Kumar http://orcid.org/0000-0001-9750-3437

Martin McKee http://orcid.org/0000-0002-0121-9683

\section{REFERENCES}

1 Jagannathan R, Patel SA, Ali MK, et al. Global updates on cardiovascular disease mortality trends and Attribution of traditional risk factors. Curr Diab Rep 2019;19:44.

2 United N. Goal 3: sustainable development knowledge platform, 2019. Available: https://sustainabledevelopment.un.org/sdg3 [Accessed 23 Sep 2019].

3 Khatib R, McKee M, Shannon $\mathrm{H}$, et al. Availability and affordability of cardiovascular disease medicines and their effect on use in highincome, middle-income, and low-income countries: an analysis of the pure study data. Lancet 2016;387:61-9.

4 Mendis S, Fukino K, Cameron A, et al. The availability and affordability of selected essential medicines for chronic diseases in six low- and middle-income countries. Bull World Health Organ 2007;85:279-88.

5 Adler AJ, Prabhakaran D, Bovet P, et al. Reducing cardiovascular mortality through prevention and management of raised blood pressure: a world heart Federation roadmap. Glob Heart 2015;10:111-22.

6 Attaei MW, Khatib R, McKee M, et al. Availability and affordability of blood pressure-lowering medicines and the effect on blood pressure control in high-income, middle-income, and low-income countries: an analysis of the pure study data. Lancet Public Health 2017;2:e411-9.

7 Chow CK, Lock K, Madhavan M, et al. Environmental profile of a community's health (epoch): an instrument to measure environmental determinants of cardiovascular health in five countries. PLoS One 2010;5:e14294.

8 Who CVD-Risk management package for low- and medium-resource settings. Available: https://apps.who.int/iris/bitstream/handle/10665/ 42621/9241545852.pdf [Accessed 1 May 2019].

9 Yusuf S, Islam S, Chow CK, et al. Use of secondary prevention drugs for cardiovascular disease in the community in high-income, middleincome, and low-income countries (the pure study): a prospective epidemiological survey. Lancet 2011;378:1231-43.

10 Teo K, Chow CK, Vaz M, et al. The prospective urban rural epidemiology (pure) study: examining the impact of societal influences on chronic noncommunicable diseases in low-, middle-, and high-income countries. Am Heart J 2009;158:1-7.

11 Yusuf S, Rangarajan S, Teo K, et al. Cardiovascular risk and events in 17 low-, middle-, and high-income countries. N Engl J Med 2014;371:818-27.

12 Corsi DJ, Subramanian SV, McKee M, et al. Environmental profile of a community's health (epoch): an ecometric assessment of measures of the community environment based on individual perception. PLoS One 2012;7:e44410.

13 World Health Organization. Who model list of essential medicines, 16th list 2019. Available: https://www.who.int/medicines/ publications/essentialmedicines/en/ [Accessed 2 Sep 2019].

14 Chow CK, Ramasundarahettige C, Hu W, et al. Availability and affordability of essential medicines for diabetes across high-income, middle-income, and low-income countries: a prospective epidemiological study. Lancet Diabetes Endocrinol 2018;6:798-808.

15 Niëns LM, Van de Poel E, Cameron A, et al. Practical measurement of affordability: an application to medicines. Bull World Health Organ 2012;90:219-27.

16 Hougaard P. Shared frailty models. in: analysis of multivariate survival data. New York, NY: Statistics for Biology and Health. Springer, 2000.

17 Joseph P, Yusuf S, Lee SF, et al. Prognostic validation of a NonLaboratory and a laboratory based cardiovascular disease risk score in multiple regions of the world. Heart 2018;104:581-7.

18 van Mourik MSM, Cameron A, Ewen M, et al. Availability, price and affordability of cardiovascular medicines: a comparison across 36 countries using WHO/HAl data. BMC Cardiovasc Disord 2010;10:25. 
19 Geldsetzer P, Manne-Goehler J, Marcus M-E, et al. The state of hypertension care in 44 low-income and middle-income countries: a cross-sectional study of nationally representative individual-level data from 1.1 million adults. Lancet 2019;394:652-62.

20 Husain MJ, Datta BK, Kostova D, et al. Access to cardiovascular disease and hypertension medicines in developing countries: an analysis of essential medicine Lists, price, availability, and affordability. J Am Heart Assoc 2020;9:e015302.

21 Chow CK, Teo KK, Rangarajan S, et al. Prevalence, awareness, treatment, and control of hypertension in rural and urban communities in high-, middle-, and low-income countries. JAMA 2013;310:959-68.
22 World Health Organization. Essential medicines. Available: http:// www.who.int/medicines/services/essmedicines_def/en/ [Accessed 7 June 2019].

23 WHO. Global action plan for the prevention and control of NCDS 2013-2020. Available: https://www.who.int/nmh/events/ncd_action_ plan/en/ [Accessed 1 Oct 2019].

24 Acosta A, Vanegas EP, Rovira J, et al. Medicine shortages: gaps between countries and global perspectives. Front Pharmacol 2019;10:763.

25 Schwalm J-D, McCready T, Lopez-Jaramillo P, et al. A communitybased comprehensive intervention to reduce cardiovascular risk in hypertension (hope 4): a cluster-randomised controlled trial. Lancet 2019;394:1231-42

26 Bansal M. Cardiovascular disease and COVID-19. Diabetes Metab Syndr 2020;14:247-50. 